\title{
Flexural Fatigue Behavior of High Volume Fly Ash Concrete with Different Cement Replacement Levels
}

\author{
S. Yuvaraj
}

\begin{abstract}
There is a need for the development of eco friendly and cost effective material for the rigid pavement construction. High volume fly ash concrete suits the pavement concrete due to its many advantages. The knowledge of fatigue behavior is essential for the design of concrete pavements. This paper describes the effect of cement replacement level on the flexural fatigue behavior of high volume fly ash concrete. High volume fly ash concrete mixtures were proportioned using low calcium fly ash and satisfying the flexural strength criteria of pavement concrete. A total of 265 beam specimens at three cement replacement levels $(0 \%, 50 \%$ and $60 \%)$ were tested under haversine wave form loading. Lognormal model was found to be satisfactory for the fatigue life distributions in all the cases. The parameters of log normal distribution model were found to be dependent on the stress level. S- $N$ relations established in this study will be a useful tool for design of high volume fly ash concrete pavement.
\end{abstract}

Index Terms--- Concrete, Fatigue, Fly Ash, Pavement, Probability Distribution.

\section{INTRODUCTION}

$\mathrm{T}$ HE understanding of the behavior of a concrete road under fatigue loading is vital for the design and the performance prediction. The fatigue behavior is influenced by various parameters such as rate of loading (Raithy et al 1974; Sparks 1982), rest period (Hilsdorf et al 1966; Raithy et al 1974; Ramakrishnan et al 1991), type of fatigue loading (Holmen 1982; Siemes 1982), range of loading (Murdock et al 1958; Awad et al 1974), material properties (Raithy et al 1974; Lee et al 1985) and the size of specimen (Bazant et al 1991). The majority of the researchers (Hilsdorf et al 1966; Ballinger 1972; Tepfers et al 1979) have developed the fatigue model relating the stress level (S) which is defined as the ratio of maximum stress applied in cyclic loading to static flexural strength, to the number of load cycles to failure(N), termed as fatigue life. This relation is commonly referred to as Wholer equation. The second form of fatigue model given by Vesic et al (1969) and Treybig et al (1977) is a power equation relating $\mathrm{S}$ and N. Jakobsen et al (1970) included the effect of ratio of minimum stress to maximum stress in cyclic loading, known as stress range (R), in the S-N relation. Hsu (1981) developed a more general expression for fatigue strength involving four variables i.e., S, N, R and period of cyclic loading (T). But the most commonly used fatigue model for design of concrete

S. Yuvaraj, Structural Engineer, Emphora Associates, Coimbatore. DOI:10.9756/BIJIEMS.8351 pavements is the one given by Wholer equation. Jointed concrete pavement design procedures adopted by many countries use fatigue models in the form of $\mathrm{S}-\mathrm{N}$ curves in conjunction with cumulative fatigue damage analysis. In the development of $\mathrm{S}-\mathrm{N}$ model it was assumed that the non dimensional term ' $S$ ' eliminates the influence of static ultimate strength of concrete and hence eliminates the effect of water-cement ratio, type and gradation of aggregate, type and amount of cement, age of concrete. But there are concerns over influence of static strength of concrete on S-N relation due to variation in fracture toughness. Lee et al (2004) have reported about significant amount of conflicting information in the literature regarding the fatigue behavior of cementitious materials and also about lack of well established test procedure for executing and evaluating fatigue tests.

The high volume fly ash concrete (HFC) is one specific type of fly ash concrete with minimum cement replacement level of $50 \%$ with fly ash (Mehta 2002), lower water to cementitious materials ratio (W/CM), and lower cement contents. Majority of the studies available till date on fatigue modeling are on conventional concrete. The applicability of data on conventional concrete to high volume fly ash concrete is questionable in view of better performance characteristics reported for HFC in literature (Gebler et al 1983, Carette et al 1993). Limited studies (Tse et al 1986; Naik et al 1994; Ramakrishnan et al 2005) are available on fatigue behavior of HFC. Tse et al (1986) have reported dependence of compression fatigue behavior on source of fly ash and cement replacement ratio. Ramakrishnan et al (2005) have developed S-N relation for HFC with cement replacement level of 58\% using third point flexural fatigue loading at a frequency of $20 \mathrm{~Hz}$.

In contrast to wide spectrum of fatigue load applications on pavements, most research projects on flexural fatigue behavior of HFC have usually been limited to a narrow range of stress level (0.61-0.9) and number of specimens at each stress level being small enough to conduct statistical analysis. Also fatigue life results for stress level above 0.85 will be of little significance for design of rigid pavement. Hence the S-N equations derived for the range of stress levels used in the literature will have limited utility.

\section{RESEARCH SigNIFICANCE AND SCOPE}

The use of HFC for mass concrete applications, especially for pavement construction will be a resource efficient, durable, cost-effective and sustainable option. In the current study, the development of mix proportions and fatigue studies were 
aimed at pavement applications. An attempt has been made to study the influence of varying percentages of cement replacements with low calcium fly ash on the fatigue behavior of HFC. Also the fatigue test results of HFC were compared with that of corresponding plain concrete (PCC). Typically cement replacement levels of $50 \%$ and $60 \%$ were used in the study for HFC. A total number of 100 PCC beams were tested under flexural fatigue. A total number of 95 specimens were used for HFC with 60\% cement replacement (HFC60) and for HFC with 50\% cement replacement (HFC50) 70 beam specimens were used. Probability distributions were determined for the fatigue life data. From regression analysis $\mathrm{S}-\mathrm{N}$ relations were established.

\section{LABORATORY INVESTIGATIONS}

\section{Materials}

Ordinary Portland cement from single batch was used in the present investigation. The coarse fraction consisted of equal fractions of crushed stones of maximum size $20 \mathrm{~mm}$ and $12 \mathrm{~mm}$ confirming to gradation specified by codal provisions (IS 383-1970). Low calcium fly ash satisfying the criteria of fineness, lime reactivity and compressive strength requirements (IS 3812-2003) was used in the investigation. Fine aggregate used was natural river sand with maximum particle size of $4.75 \mathrm{~mm}$ confirming to zone-II gradation (IS 383-1970). Polycarboxylic based superplasticizer was used as high range water reducing admixture (HRWA) to get the desired workability. The optimum dosage of superplasticizer was fixed from compaction factor test (IS1199-1959). Since the mix was sticky target compaction factor was kept in the range of 0.9 to 0.91 .

\section{Mixture Proportions}

Trial mixes were developed to achieve M35 grade HFC at optimum cement replacement level of $60 \%$ at a water to cementitious material ratio $(\mathrm{w} / \mathrm{cm})$ of 0.3 and satisfying the criteria of minimum flexural strength for pavement concrete i.e., $3.8 \mathrm{~N} / \mathrm{mm}^{2}$ (IRC:SP:62-2004) . Corresponding concrete with $0 \%$ replacement was used as reference concrete. The mix proportions for HFC50 and PCC were determined by absolute volume method keeping $\mathrm{w} / \mathrm{cm}$ ratio and weight of cemnetitious materials constant.The quantity of fine aggregate was adjusted for HFC50 and HFC60 for the difference in specific gravity value of cement and fly ash. Mix proportions for all the three concrete mixes are presented in Table 1.

Table 1: Mixture Proportions of Concrete

\begin{tabular}{|c|c|c|c|}
\hline $\begin{array}{l}\text { Mixture } \\
\text { Components }\end{array}$ & PCC & HFC50 & HFC60 \\
\hline Cement (OPC 53 grade) in $\mathrm{kg} / \mathrm{m}^{3}$ & 440 & 220 & 176 \\
\hline Class F fly ash in $\mathrm{kg} / \mathrm{m}^{3}$ & 0 & 220 & 264 \\
\hline Water in $\mathrm{kg} / \mathrm{m}^{3}$ & 132 & 132 & 132 \\
\hline Superplasticizer in liter $/ \mathrm{m}^{3}$ & 15.4 & 3.5 & 3.5 \\
\hline Saturated surface dry sand in $\mathrm{kg} / \mathrm{m}^{3}$ & 937.6 & 871 & 858.2 \\
\hline $\begin{array}{l}\text { Saturated surface dry coarse aggregate } \\
\text { in } \mathrm{kg} / \mathrm{m}^{3}\end{array}$ & 1059 & 1059 & 1059 \\
\hline
\end{tabular}

\section{Test Specimens}

Compressive strength of concrete was determined by means of cube specimens of size $150 \mathrm{~mm} \times 150 \mathrm{~mm} \times 150 \mathrm{~mm}$.
The beam specimens of size $75 \mathrm{~mm} \times 100 \mathrm{~mm} \times 500 \mathrm{~mm}$ confirming to published literature (Ramakrishnan et al 2005) and ASTM C78-10 were used for static and fatigue testing in flexure. Both static and fatigue tests in flexure were conducted using third point loading with effective span of the beam as $400 \mathrm{~mm}$. Minimum number of fatigue test specimens at each stress level was kept at 10 in anticipation of larger scatter in fatigue test results.

\section{Test Procedure and Test Results}

\section{Static Testing}

The static compressive and flexural strength tests were conducted as per the standard test procedures (IS 516-1959). Both compressive strength and flexural strength values were taken as mean value of six specimens. 28 day Compressive strengths of PCC, HFC50 and HFC60 were 62.3MPa, $52.1 \mathrm{MPa}$ and $40.8 \mathrm{MPa}$ respectively. Corresponding 28 day flexural strength values were 6.9MPa, 6.4MPa and 5.3MPa respectively.

\section{Fatigue Testing}

The fatigue test was conducted using haversine wave loading at a frequency of $4 \mathrm{~Hz}$. Typical loading pattern is shown in Figure 1. All the fatigue specimens were tested after 90 days from casting so as to give allowance for uniform drying and sufficient strength gain. Specimens were cured for 28 days by ponding method and then covered with polythene bags up to 90 days under room conditions. Minimum stress in fatigue loading was maintained at $1 \%$ of maximum stress to prevent any possible movement of specimens at support and to simulate residual stresses in the pavement to a certain degree. The lower limit of $\mathrm{S}$ was based on the criteria, when none of the test specimens failed even after the application of $10^{5}$ cycles of fatigue loading. Since the present investigation was not aimed at determination of endurance limit and also frequency of loading used was low, number of load cycles applied was limited to $10^{5}$. All the specimens exhibited a brittle failure in the flexure zone. Constant amplitude Fatigue test results for PCC, HFC50 and HFC60 are listed in Tables 2 to 4 respectively.

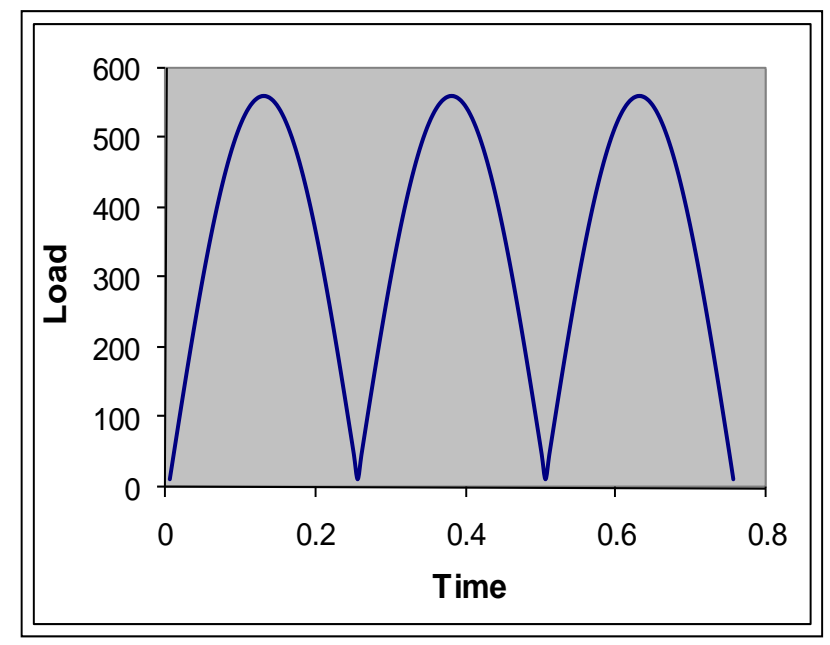

Figure 1: Fatigue Loading Pattern 
Table 2: Fatigue Life of PCC at Different Stress Levels

\begin{tabular}{|l|c|c|c|c|c|c|c|l|}
\hline Test specimen no. & $\mathrm{S}=0.85$ & $\mathrm{~S}=0.81$ & $\mathrm{~S}=0.76$ & $\mathrm{~S}=0.71$ & $\mathrm{~S}=0.65$ & $\mathrm{~S}=0.61$ & $\mathrm{~S}=0.57$ & $\mathrm{~S}=0.53$ \\
\hline 1 & 22 & 84 & 158 & 1327 & 5289 & 16488 & 46582 & $100000^{*}$ \\
\hline 2 & 43 & 97 & 284 & 1489 & 7213 & 20312 & 48270 & $100000^{*}$ \\
\hline 3 & 69 & 105 & 312 & 2596 & 8863 & 22268 & 52164 & $100000^{*}$ \\
\hline 4 & 78 & 152 & 382 & 3642 & 10322 & 34511 & 54416 & $100000^{*}$ \\
\hline 5 & 82 & 184 & 411 & 4149 & 12723 & 39920 & 56005 & $100000^{*}$ \\
\hline 6 & 94 & 198 & 474 & 5218 & 16523 & 46718 & 66012 & $100000^{*}$ \\
\hline 7 & 102 & 288 & 578 & 6629 & 18708 & 51512 & 73676 & $100000^{*}$ \\
\hline 8 & 110 & 432 & 694 & 8383 & 20391 & 61512 & 80520 & $100000^{*}$ \\
\hline 9 & 122 & 682 & 916 & 9558 & 21262 & 77812 & 81891 & $100000^{*}$ \\
\hline 10 & 138 & 730 & 1182 & 12009 & 23992 & 81800 & $100000^{*}$ & $100000^{*}$ \\
\hline 11 & ---- & --- & --- & ---- & 24771 & 92477 & $100000^{*}$ & $100000^{*}$ \\
\hline 12 & ---- & --- & ---- & --- & 27344 & $100000^{*}$ & $100000^{*}$ & $100000^{*}$ \\
\hline 13 & ---- & ---- & ---- & --- & 32811 & $100000^{*}$ & $100000^{*}$ & $100000^{*}$ \\
\hline 14 & ---- & ---- & --- & --- & 40887 & $100000^{*}$ & $100000^{*}$ & $100000^{*}$ \\
\hline 15 & --- & ---- & --- & --- & 44816 & $100000^{*}$ & $100000^{*}$ & $100000^{*}$ \\
\hline
\end{tabular}

*specimen did not fail after the application of given number of cycles of loading -- data not available

Table 3: Fatigue Life of HFC50 at Different Stress Levels

\begin{tabular}{|l|r|r|r|r|r|r|l|}
\hline Test specimen no. & $\mathrm{S}=0.8$ & $\mathrm{~S}=0.75$ & $\mathrm{~S}=0.7$ & $\mathrm{~S}=0.65$ & $\mathrm{~S}=0.6$ & $\mathrm{~S}=0.55$ & $\mathrm{~S}=0.50$ \\
\hline 1 & 34 & 157 & 1693 & 5540 & 16884 & 30740 & $100000^{*}$ \\
\hline 2 & 40 & 211 & 1810 & 8762 & 20225 & 36575 & $100000^{*}$ \\
\hline 3 & 52 & 223 & 2289 & 10220 & 23841 & 40724 & $100000^{*}$ \\
\hline 4 & 57 & 328 & 2632 & 12392 & 26684 & 42095 & $100000^{*}$ \\
\hline 5 & 74 & 378 & 2890 & 15415 & 30080 & 46390 & $100000^{*}$ \\
\hline 6 & 86 & 847 & 3401 & 19662 & 31185 & 55180 & $100000^{*}$ \\
\hline 7 & 112 & 1023 & 3622 & 21880 & 33542 & 60371 & $100000^{*}$ \\
\hline 8 & 122 & 1179 & 4055 & 22720 & 35820 & 65940 & $100000^{*}$ \\
\hline 9 & 135 & 1328 & 4138 & 24241 & 38415 & 81055 & $100000^{*}$ \\
\hline 10 & 168 & 1831 & 5024 & 29375 & 39730 & $100000^{*}$ & $100000^{*}$ \\
\hline
\end{tabular}

* specimen did not fail after the application of given number of cycles of loading

Table 4: Fatigue Life of HFC60 at Different Stress Levels

\begin{tabular}{|l|c|c|c|c|c|c|c|}
\hline Test specimen no. & $\mathrm{S}=0.80$ & $\mathrm{~S}=0.75$ & $\mathrm{~S}=0.7$ & $\mathrm{~S}=0.65$ & $\mathrm{~S}=0.60$ & $\mathrm{~S}=0.54$ & $\mathrm{~S}=0.50$ \\
\hline 1 & 44 & 78 & 312 & 4159 & 5324 & 18785 & $100000^{*}$ \\
\hline 2 & 48 & 102 & 422 & 5802 & 6852 & 19084 & $100000^{*}$ \\
\hline 3 & 52 & 146 & 584 & 6802 & 7102 & 21039 & $100000^{*}$ \\
\hline 4 & 65 & 182 & 886 & 7759 & 8404 & 22259 & $100000^{*}$ \\
\hline 5 & 72 & 212 & 1092 & 8759 & 12723 & 29384 & $100000^{*}$ \\
\hline 6 & 88 & 292 & 1109 & 9259 & 14785 & 32911 & $100000^{*}$ \\
\hline 7 & 92 & 344 & 1243 & 10014 & 15680 & 45512 & $100000^{*}$ \\
\hline 8 & 99 & 459 & 1422 & 12008 & 22348 & 62214 & $100000^{*}$ \\
\hline 9 & 112 & 582 & 1586 & 14620 & 28109 & 68743 & $100000^{*}$ \\
\hline 10 & 120 & 889 & 1704 & 14882 & 36891 & 76544 & $100000^{*}$ \\
\hline 11 & --- & --- & 1959 & 16822 & 45841 & 82477 & $100000^{*}$ \\
\hline 12 & --- & ---- & 2390 & 16822 & 49869 & 86792 & $100000^{*}$ \\
\hline 13 & ---- & --- & 3532 & 18826 & 52113 & $100000^{*}$ & $100000^{*}$ \\
\hline 14 & ---- & --- & 4426 & 23426 & 59641 & $100000^{*}$ & $100000^{*}$ \\
\hline 15 & ---- & --- & 3962 & 28110 & 65869 & $100000^{*}$ & $100000^{*}$ \\
\hline
\end{tabular}

* specimen did not fail after the application of given number of cycles of loading

-- data not available

\section{Probability Analysis of Fatigue Test Results}

Since the fatigue lives for all the concrete mixes showed larger scatter, an attempt to determine the probabilistic distributions was made. Few researchers (Oho 1991; Shi et al 1993) have developed Weibull distribution models for fatigue lives at different stress levels. In the present study lognormal distribution models were developed and verified at all the stress levels. Conservatively for few specimens having fatigue life more than $10^{5}$ cycles, the value has been considered as $10^{5}$ cycles in the probability analysis.

\section{A. Determination of Lognormal Distribution Model}

The probability density function of lognormal distribution model (Soong, 2004) is given by equation (1). The parameters of lognormal distributions are $\mu$ and $\sigma$ which are mean and 
standard deviation of observed ln $(\mathrm{N})$ values respectively. In the equation (1), ' $\mathrm{X}$ ' represents $\ln (\mathrm{N})$ values.

$$
f(N)=\frac{1}{N \sqrt{2 \pi \sigma^{2}}} \exp \left[-\frac{(X-\mu)^{2}}{2 \sigma^{2}}\right]
$$

\section{B. Model Verification}

Probabilistic models developed in the present investigation were tested using Kolmogorov-Smirnov test (Soong, 2004). For conducting this test, the test statistic $\mathrm{D}_{2}$ was calculated using equation (2) in which $\mathrm{F}^{\mathrm{O}}\left(\mathrm{N}_{\mathrm{j}}\right)$ is the observed distribution of $\mathrm{N}$ and $\mathrm{F}_{\mathrm{N}}\left(\mathrm{N}_{\mathrm{j}}\right)$ is the hypothesized distribution of $\mathrm{N}$ and $\mathrm{m}$ is the total number of specimens.

$$
\mathrm{D}_{2}=\max _{\mathrm{j}=1}^{\mathrm{m}}\left[\left|\mathrm{F}^{\circ}\left(\mathrm{N}_{\mathrm{j}}\right)-\mathrm{F}_{\mathrm{N}}\left(\mathrm{N}_{\mathrm{j}}\right)\right|\right]
$$

The $D_{2}$ values were compared with critical $D_{2}$ for the given sample size and significance level of $5 \%$. If the test statistic $\mathrm{D}_{2}$ was less than the critical $D_{2}$, the model was accepted. The verification of lognormal distribution for all the types of concretes at different stress levels along with parameters of lognormal distribution is given in Table 5 . The lognormal model was accepted in all the cases.

\begin{tabular}{|c|c|c|c|c|c|c|}
\hline $\begin{array}{l}\text { Type of } \\
\text { concrete }\end{array}$ & $\begin{array}{l}\text { Stress } \\
\text { level }\end{array}$ & $\mu$ & $\sigma$ & $\begin{array}{l}\text { Maximum } \mathrm{D}_{2} \text { from lognormal } \\
\text { distribution }\end{array}$ & $\begin{array}{l}\mathrm{D}_{2} \text { for } 5 \% \text { significance } \\
\text { level }\end{array}$ & Inference \\
\hline \multirow[t]{7}{*}{ PCC } & 0.85 & 4.3450 & 0.5501 & 0.1449 & 0.41 & \multirow{19}{*}{$\begin{array}{l}\text { Lognormal models are accepted in all } \\
\text { the cases }\end{array}$} \\
\hline & 0.81 & 5.4036 & 0.7867 & 0.1583 & 0.41 & \\
\hline & 0.76 & 6.1377 & 0.5925 & 0.0781 & 0.41 & \\
\hline & 0.71 & 8.3841 & 0.7565 & 0.1230 & 0.41 & \\
\hline & 0.65 & 9.7882 & 0.6293 & 0.0739 & 0.34 & \\
\hline & 0.61 & 10.8915 & 0.6321 & 0.1628 & 0.34 & \\
\hline & 0.57 & 11.2150 & 0.3007 & 0.1609 & 0.34 & \\
\hline \multirow[t]{6}{*}{ HFC50 } & 0.8 & 4.3520 & 0.5407 & 0.1161 & 0.41 & \\
\hline & 0.75 & 6.2992 & 0.8874 & 0.1593 & 0.41 & \\
\hline & 0.7 & 8.0000 & 0.3629 & 0.1154 & 0.41 & \\
\hline & 0.65 & 9.6292 & 0.5306 & 0.1072 & 0.41 & \\
\hline & 0.6 & 10.2632 & 0.2822 & 0.1235 & 0.41 & \\
\hline & 0.55 & 10.8686 & 0.3687 & 0.1314 & 0.41 & \\
\hline \multirow[t]{6}{*}{ HFC60 } & 0.80 & 4.3158 & 0.3599 & 0.1445 & 0.41 & \\
\hline & 0.75 & 5.5329 & 0.7742 & 0.0901 & 0.41 & \\
\hline & 0.70 & 7.2237 & 0.7795 & 0.0868 & 0.34 & \\
\hline & 0.65 & 9.3603 & 0.5369 & 0.0757 & 0.34 & \\
\hline & 0.60 & 9.9538 & 0.8700 & 0.1208 & 0.34 & \\
\hline & 0.54 & 10.7820 & 0.6580 & 0.1462 & 0.34 & \\
\hline
\end{tabular}

Table 5: Kolmogorov-Smirnov Test for Lognormal Distribution for Fatigue Life at Different Stress Levels

\section{DETERMinATION OF S-N RELATIONS}

S-N relations have got significant role in design of rigid pavements. In the present study the relations were developed by performing regression analysis on fatigue test data. The S$\mathrm{N}$ curves determined for the three concrete mixes are shown in Figure 2. S-N relation for HFC50 closely matches with the S$\mathrm{N}$ curve given in the literature (IRC58-2011) for conventional concrete. All the plots of $\mathrm{S}$ versus $\mathrm{N}$ exhibited non linear trends with relatively higher value coefficient of correlation (R) for a fatigue data. S-N relations were typically logarithmic in nature. S-N relations obtained for PCC, HFC50 and HFC60 are given by equations (3) to (5) respectively. Significant difference in fatigue behavior of PCC and HFC can be observed from the S-N plots. This can be attributed to the difference in the static strengths. The fatigue strength increased with the decrease in cement replacement level. The dependency of S-N relation on the strength of concrete is quite evident from the $\mathrm{S}-\mathrm{N}$ relations. Using constant variance method 95\% confidence limits were determined. Upper and lower confidence limits along with S-N curve for PCC, HFC50 and HFC60 are shown in Figures 3 to 5 respectively.

$\begin{array}{lll}S=-0.0358 \operatorname{Ln}(N)+0.995 & \left(R^{2}=0.93\right) & - \\ S=-0.0345 \operatorname{Ln}(N)+0.96 & \left(R^{2}=0.91\right) & ------ \\ S & (3) \\ S=-0.0338 \operatorname{Ln}(N)+0.94 & \left(R^{2}=0.88\right) & -------(5)\end{array}$

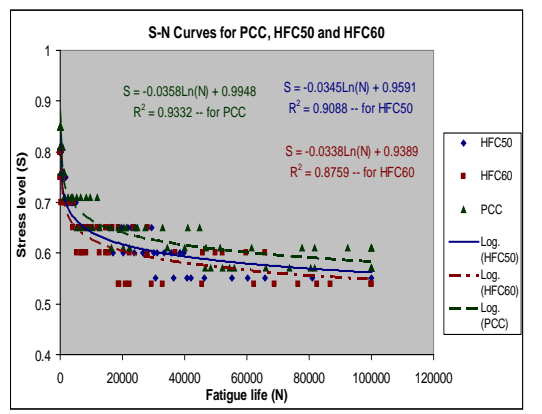

Figure 2: S-N Curves for PCC, HFC50 and HFC60

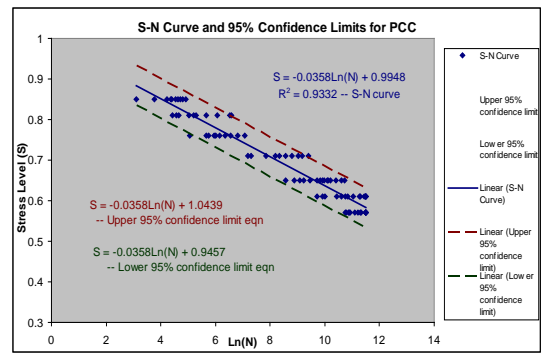

Figure 3: S-N Curve and 95\% Confidence Limits for PCC 


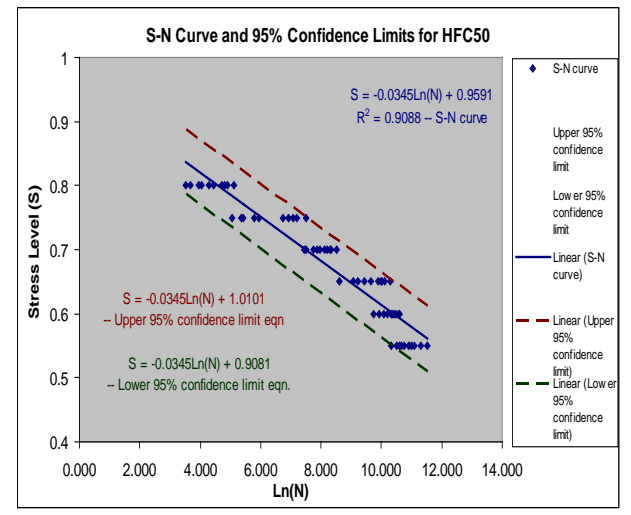

Figure 4: S-N Curve and 95\% Confidence Limits for HFC50

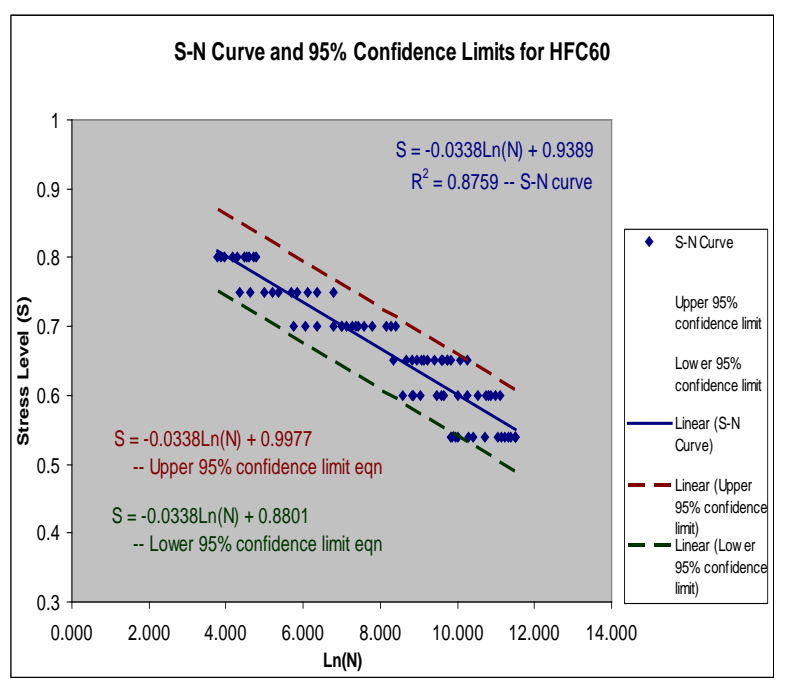

Figure 5: S-N Curve and 95\% Confidence Limits for HFC60

\section{CONCLUSION}

Based on experimental investigations following conclusions are made.

- The concrete satisfying static flexural strength criteria of pavement concrete can be obtained at cement replacement level of $60 \%$ with low calcium fly ash.

- Lognormal distribution model was found to be satisfactory for probability distribution of fatigue life at all stress levels for both PCC and HFC.

- Parameters of lognormal model were found to be dependent on the type of concrete mix and the stress level.

- S-N relations obtained from regression analysis for the three types of concrete mixes are as follows:

$$
\begin{aligned}
& S=-0.0358 \operatorname{Ln}(N)+0.995 \quad------ \text { for PCC } \\
& S=-0.0345 \operatorname{Ln}(N)+0.96 \quad-----f o r ~ H F C 50 \\
& S=-0.0338 \operatorname{Ln}(N)+0.94 \quad----f o r \text { HFC60 }
\end{aligned}
$$

- The fatigue strength of concrete mix decreases with the increase in cement replacement level.

\section{ACKNOWLEDGEMENT}

The financial support under Research Promotion Scheme from All India Council for Technical Education, New Delhi, India, is gratefully acknowledged.

\section{REFERENCES}

[1] K.Aas-Jakobsen, "Fatigue of Concrete Beams and Columns", NTH Institute of Betonkonstruksjoner, Trondheim, Bulletin No. 70-1, Norway, 1970.

[2] ASTM C78-10. "American Standard Test Method for Flexural Strength of Concrete (using simple beam with third point loading)".

[3] M.E. Awad and H.K. Hilsdorf, "Strength and Deformation Characteristics of Plain Concrete Subjected to High Repeated and Sustained Loads”, ACI Special Publication, SP-41, Pp. 1-14, 1974.

[4] C.A. Ballinger, "Cumulative Fatigue Damage Characteristics of Plain Concrete”, Highway Research Record, Vol. 370, Pp. 48-60, 1972.

[5] Byung Hwan Oh, "Fatigue-Life Distributions of Concrete for Various Stress Levels”, ACI Materials Journal, Vol. 88, No. 2, Pp. 122-128, 1991.

[6] G.G. Carette, A. Bilodeau, R.L. Chevrier and V.M. Malhotra, "Mechanical Properties of Concrete Incorporating High Volumes of Fly Ash From Sources in the U.S”, ACI Materials Journal, Vol. 90, No. 6, Pp. 535-544, 1993.

[7] S.H. Gebler and P. Klieger, "Effect of Fly Ash on Physical Properties of Concrete”, ACI Special Publication, SP-91, Pp. 1-50, 1986.

[8] H.K. Hilsdorf and C.E. Kesler, "Fatigue Strength of Concrete under Varying Flexural Stresses”, ACI Journal Proceedings, Vol. 63, No.10, Pp. 1059-1076, 1996.

[9] J.O. Holmen, "Fatigue of Concrete by Constant and Variable Amplitude Loading”, ACI Special Publication, SP-75, Pp. 71-110, 1982.

[10] T.T.C. Hsu, "Fatigue of Plain Concrete", ACI Journal Proceeding, Vol. 78, No. 4, Pp. 292-305, 1981.

[11] IRC:58-2011, "Guidelines for the Design of Rigid Pavements for Highways”, Indian Roads Congress, New Delhi, India.

[12] IRC:SP:62-2004, "Guidelines for the design and Construction of Cement Concrete Pavements for Rural Roads”, Indian Roads Congress, New Delhi, India.

[13] IS:383-1970, "Specifications for Coarse and Fine aggregates from Natural Sources for Concrete”, Bureau of Indian Standards, New Delhi, India.

[14] IS:516-1959, "Method of Test for Strength of Concrete". Bureau of Indian Standards, New Delhi, India.

[15] IS:3812 (Part 1)-2003, "Pulverized Fuel ash-Specification for use as Pozzolana in Cement, Cement mortar and Concrete”, Bureau of Indian Standards, New Delhi, India.

[16] IS:1199-1959, "Methods of Sampling and Analysis of Concrete”, Bureau of Indian Standards, New Delhi, India.

[17] D.Y. Lee, J.J.F. Yang and F.W.Klaiber, "Fatigue Behavior of Superplasticized Concrete", ASTM Cement, Concrete and Aggregates, CCAGDP, Vol. 7, No. 1, Pp. 19-24, 1985.

[18] M.K. Lee and B.I.G. Barr, "An overview of the fatigue behavior of plain and fibre reinforced concrete”, Cement \& Concrete Composites Journal, Vol. 26, Pp. 299-305, 2004.

[19] J.W. Murdock and C.E.Kesler, "Effect of Range of Stress on Fatigue Strength of Plain Concrete Beams”, ACI Journal Proceedings, Vol. 55, No. 2, Pp. 221-231, 1958.

[20] T.R. Naik and S.S. Singh, "Fatigue Property of Concrete with and without mineral admixtures”, ACI Special Publication, SP-144, Pp. 269288, 1994.

[21] P.K. Mehta, "High Performance, High Volume Fly Ash Concrete for Sustainable Development”, Proceedings of International Workshop on Sustainable Development and Concrete Technology, 2004.

[22] K.D. Raithy and J.W. Galloway, "Effect of Moisture Condition, Age and Rate of Loading on Fatigue of Plain Concrete", ACI Special Publication, SP-41, Pp. 15-34, 1994.

[23] V. Ramakrishnan and B.J. Lokvik, "Fatigue Strength and Endurance Limit of Plain and Fibre Reinforced Concretes-A Critical Review", Proceedings of the International Symposium on Fatigue and Fracture in Steel and Concrete Structures, Madras, India, Pp. 381-407, 1991.

[24] V. Ramakrishnan, V.M. Malhotra and W.S. Langley, "Comparative Evaluation of Flexural Fatigue Behavior of High Volume Fly Ash and Plain Concrete”, ACI Special Publication, SP-229, Pp. 351-368, 2005. 
[25] X.P. Shi, T.F. Fwa and S.A. Tan, "Flexural Fatigue Strength of Plain Concrete”. ACI Materials Journal, Vol. 90, No. 5, Pp. 435-440, 1993.

[26] A.J.M. Siemes, "Miner's Rule with Respect to Plain Concrete Variable Amplitude Tests”. ACI Special Publication, SP-75, Pp. 343-372, 1982.

[27] P.R. Sparks, "The influence of Rate of Loading and Material Variability on the Fatigue Characteristics of Concrete", ACI Special Publication, SP-75, Pp. 331-341, 1982.

[28] R. Tepfers and T. Kutti, "Fatigue Strength of Plain, Ordinary, and Lightweight Concrete”, ACI Journal Proceeding, Pp. 635-652, 1979.

[29] H.J. Treybig, B.F. McCullough, P. Smith and H. Von Quintus, “Overlay Design and Reflection Cracking Analysis for Rigid Pavements. Development of New Design Criteria”, FHWA Report No. FHWA-RD77-76, 1977.

[30] E.W. Tse, D.Y. Lee and F.W. Klaiber, "Fatigue behavior of Concrete Containing Fly ash”. ACI Special Publication, SP-91, Pp. 273-289, 1986.

[31] T.T. Soong, "Fundamentals of Probability and Statistics for Engineers", John Wiley \& Sons Ltd, England, 2004.

[32] A.S. Vesic and S.K. Saxena, "Analysis of Structural Behavior of Road Test Rigid Pavements”, Highway Research record, Vol. 291, Pp. 156158, 1969.

[33] Zdenek, P. Bazant and Kangming Xu, "Size Effect in Fatigue Fracture of Concrete”, ACI Materials Journal, Vol. 88, No. 4, Pp. 390-399, 1991. 